\title{
Calibration of urethra with anti-scar gel as a new preventive method for stricture recurrence after urethroplasty performed due to refractory anterior urethral stricture disease
}

\author{
Wojciech Perdzyński, Marek Adamek \\ Department of Reconstructive Surgery of the Male Genitourinary Tract, Damian's Hospital, Warsaw, Poland
}

Citation: Perdzyński W, Adamek M. Calibration of urethra with anti-scar gel as a new preventive method for stricture recurrence after urethroplasty performed due to refractory anterior urethral stricture disease. Cent European J Urol. 2020; 73: 80-90.

Article history

Submitted: Oct. 14, 2019

Accepted: March 3, 2020

Published online: March 23, 2020

Corresponding author Wojciech Perdzyński 79A/64 Koszykowa Street 02-008 Warsaw, Poland mobile phone:

+48601285917

perdzynski@perdzynski.pl
Introduction The aim of this article was to determine if scar contraction can be prevented by calibration of urethra with anti-scar gel (ASG).

Material and methods The authors operated on 36 men with recurrent urethral strictures (US). Strictures were localized in the penile $(n=26)$, penile and bulbar (8) or in the bulbar (2) part of the urethra. In 34 patients, dorsal inlay buccal mucosa graft urethroplasty (BMGU) was performed and in the remaining 2 patients dorsal onlay BMGU was performed. First calibration was done one month after operation by $3.5 \mathrm{~mm}$ hegar with ASG. Patients were instructed how to perform this action and repeated this action for 4-6 weeks. Then, every 4-6 weeks, the size of the calibrator was increased by $0.5 \mathrm{~mm}$ up to $6.0 \mathrm{~mm}$, if it was introduced with ease. Results were assessed by uroflowmetry and urethral calibration. Afterwards, calibrations were carried out twice a week for 6 months and then once a week for another 6 months followed by once a month.

Results Mean follow-up was 61 months. In uroflowmetry examination, voiding improved in all patients. Both preoperative mean Qmax and mean Qavg increased, the former from 6.2 to $22.5 \mathrm{ml} / \mathrm{s}$, the latter from 4.3 to $12.4 \mathrm{ml} / \mathrm{s},(\mathrm{p}<0.001)$, at 12 months post-operation. Mean post-void residual volume (PVR) decreased from $89 \mathrm{ml}$ before operation to $10 \mathrm{ml},(p<0.001)$, at 12 months post-operation. Mean inner urethral size increased from $3.9 \mathrm{~mm}$ one month post-operation to $5.4 \mathrm{~mm},(p<0.001), 9$ months postoperation. No recurrent US was detected in any of the patients.

Conclusions Routine calibration with ASG prevents scar contraction after urethroplasty in the long-term. Calibration of urethra with ASG is a safe and effective method of postoperative management.

Key Words: urethral stricture 〈〉 urethral calibration « buccal mucosa graft urethroplasty 〈 hypospadias (» lichen sclerosus «) wound healing «) scar contracture «) anti-scar gel

\section{INTRODUCTION}

Buccal mucosa graft urethroplasty (BMGU) is the 'gold standard' in operations of primary and recurrent urethral stricture disease (USD) when a strictured segment is long [1-5].

Recurrent strictures which remain a challenge for reconstructive urologists were assessed as having an increased risk of failure [1, 3, 6-11]. Some authors opinions are contrary to this and they report that risk of primary and repeat operations is the same $[2,4,12]$. Early results of BMGU were assessed as satisfactory if the restricture rate was between 12 and $18 \%$ [1, 2, 4, 6]. Long-term results were not optimistic. At 5, 10 and 15 years after BMGU, stricture recurrence rates were $21 \%, 31 \%, 58 \%$, respectively, which means that a steady deterioration with time was observed $[13,14,15]$. This is why patients 
need postoperative control lasting many years [9, $14,15,16,17]$. Apart from patients after failed operations for hypospadias who are predisposed for USD recurrence (fibrotic skin, poor tissue vasculature) $[1,6,9,17]$, other causes of deterioration with time, especially those in common with penile and bulbar urethra, were not described in the literature. The authors of this report hypothesized that the contraction of scars formed after BMGU could be the reason for urethral stricture (US). If this was proven, the results of the 'gold standard' operation for recurrent USD could be improved by a routine calibration of urethra with anti-scar gel (ASG). In this report, calibrators of the same size as the actual inner urethral size (IUS) covered with ASG were inserted in the early phase of wound healing to prevent scar contraction.

\section{MATERIAL AND METHODS}

From January 2010 to June 2018, the authors operated on 36 men with recurrent USD who had a history of urethral dilatations, direct vision internal ure-

Table 1. Clinical characteristics of patients operated elsewhere and admitted with recurrent USD (list of previous operations is shown)

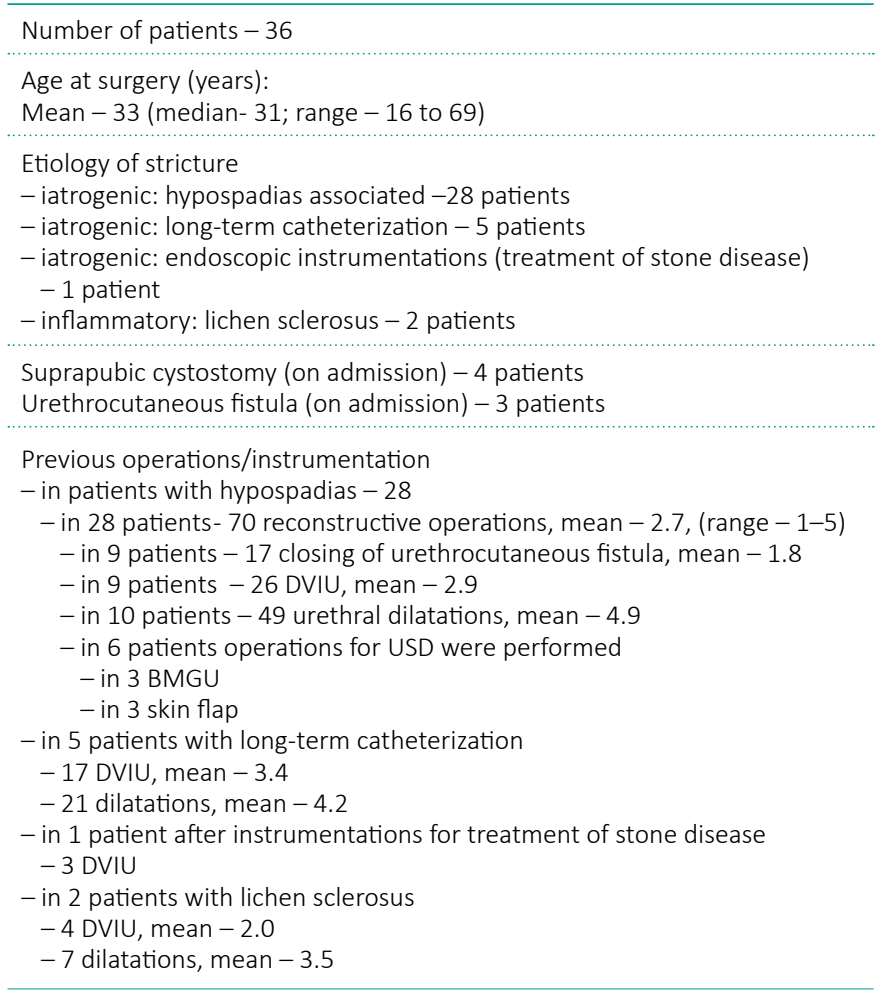

USD - urethral stricture disease; DVIU - direct vision internal urethrotomy; BMGU - buccal mucosa graft urethroplasty throtomies (DVIU) and open operations performed elsewhere. Clinical characteristics of these patients and a list of previous operations are presented in Table 1. Surgical characteristics of the patients operated on by the authors (BMGU) and after a routine postoperative treatment with ASG (last follow-up consultations - June 2019) are presented in Table 2. Preoperative assessment of medical history, physical examination, blood and urine tests were done. Diagnosis of USD was confirmed by ascending urethrography (Figure 1) and by uroflowmetry (Figure 2).

Table 2. Surgical characteristics of patients with recurrent USD after BMGU performed from January 2010 to June 2018

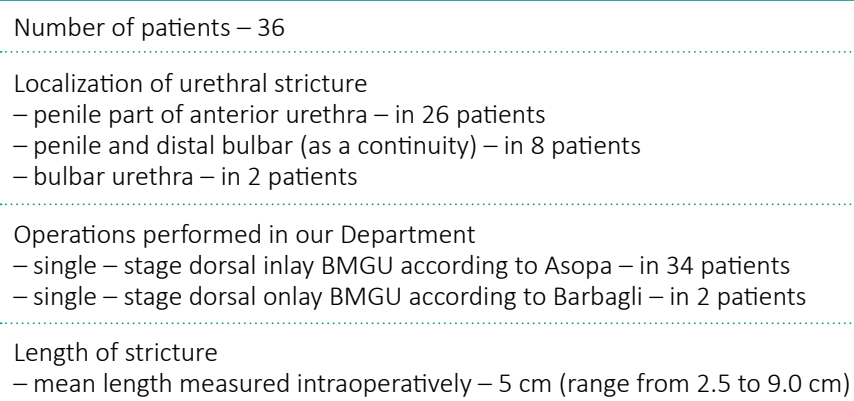

BMGU - buccal mucosa graft urethroplasty; USD - urethral stricture disease, ASG - anti-scar gel

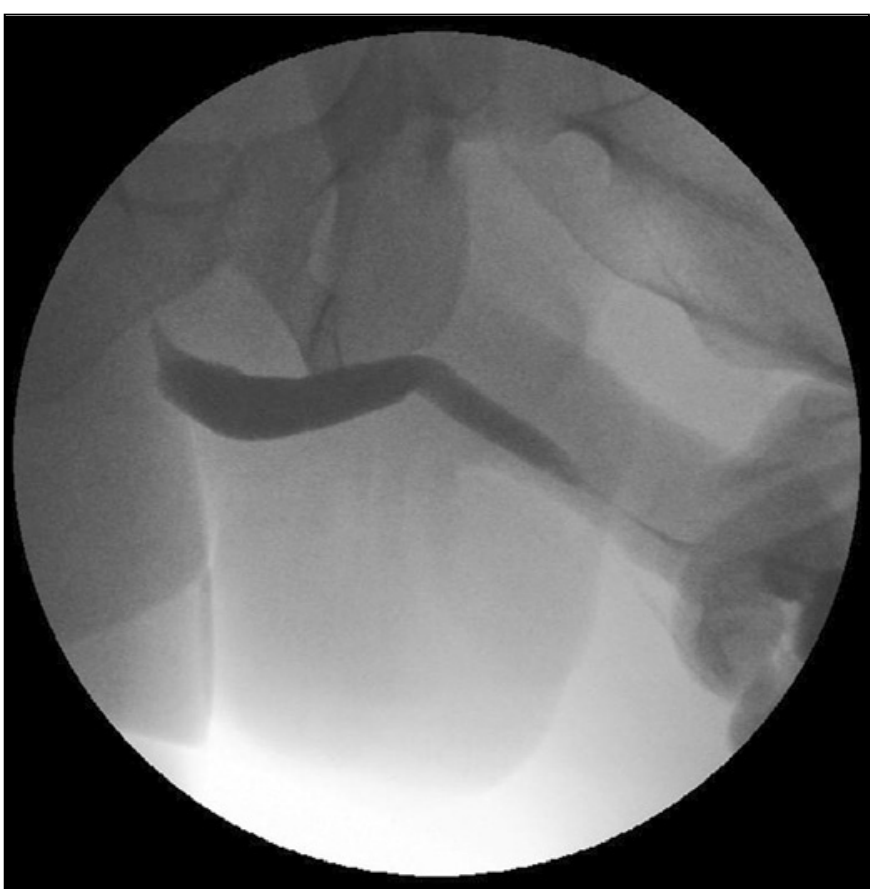

Figure 1. Ascending urethrography - stricture in the penile urethra. The patient after 3 failed operations for peno-scrotal hypospadias, after 3 DVIU and one operation for the urethral stricture with a skin flap.

DVIU - direct vision internal urethrotomy 


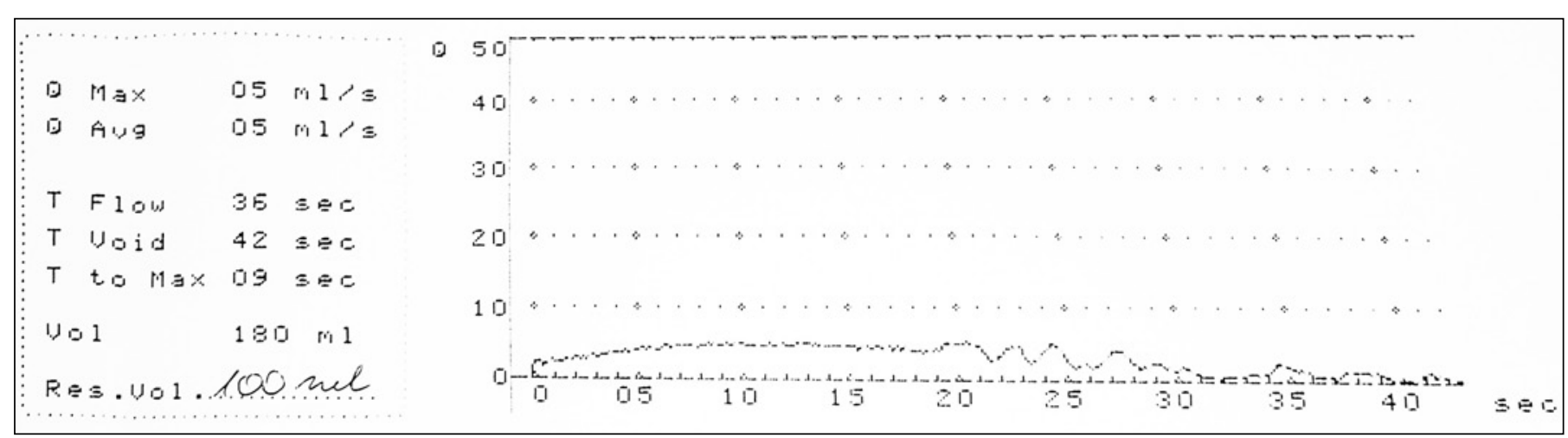

Figure 2. Uroflowmetry before operation: Qmax-5.0 ml/s, Qavg-5.0 ml/s, flow time-36.0 s, voided volume-180.0 ml, PVR $-100.0 \mathrm{ml}$.

Qmax - maximal urethral flow; Qavg-average urethral flow; PVR-post-void residual volume

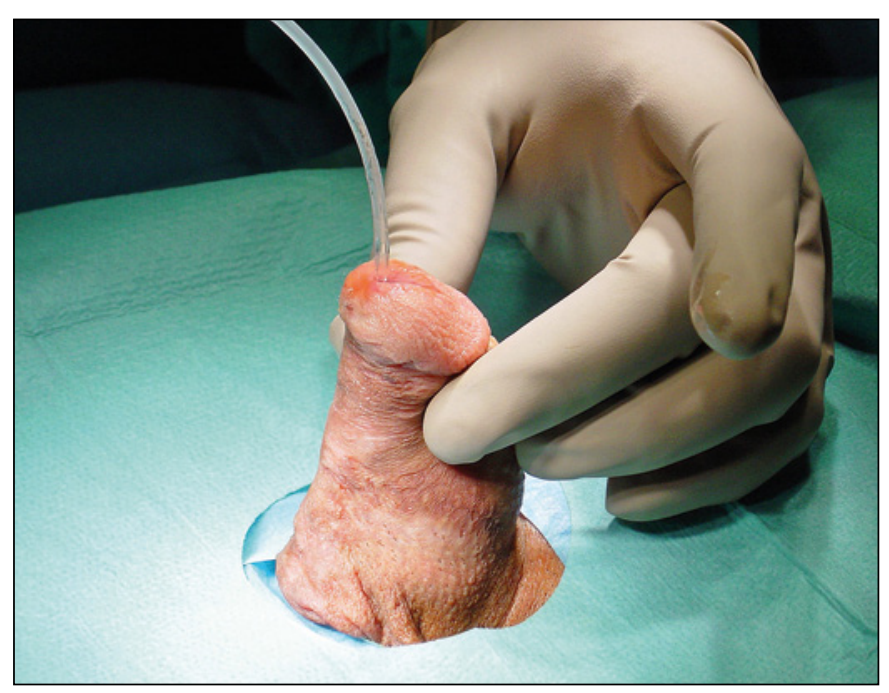

Figure 3. Catheter size 6.0 Fr (2 $\mathrm{mm})$ is introduced into urethra.

According to the method by Asopa [18], a singlestage dorsal inlay BMGU was performed by senior surgeon (WP) in 34 patients with US in penile (in 24) and penile and distal bulbar as a continuity (in 8). The operation was performed under general anesthesia, in the supine position, a thin calibrator or a catheter was introduced into urethra (Figure 3). Longitudinal incision of skin and tunica dartos on the lower surface of the penis (if necessary on anterior surface of the scrotum) followed by longitudinal, midline incision of the ventral surface of the urethra (incision is always longer than the strictured segment) was performed (Figure 4). Periurethral and urethral fibrous tissues were excised. Then the incision of the dorsal urethral wall in midline to expose tunica albuginea of corpora cavernosa and separation with lateral mobilization of two parts of urethral plate creating a bed for buccal mucosal graft implantation was performed (Figure 5). Buccal mu-

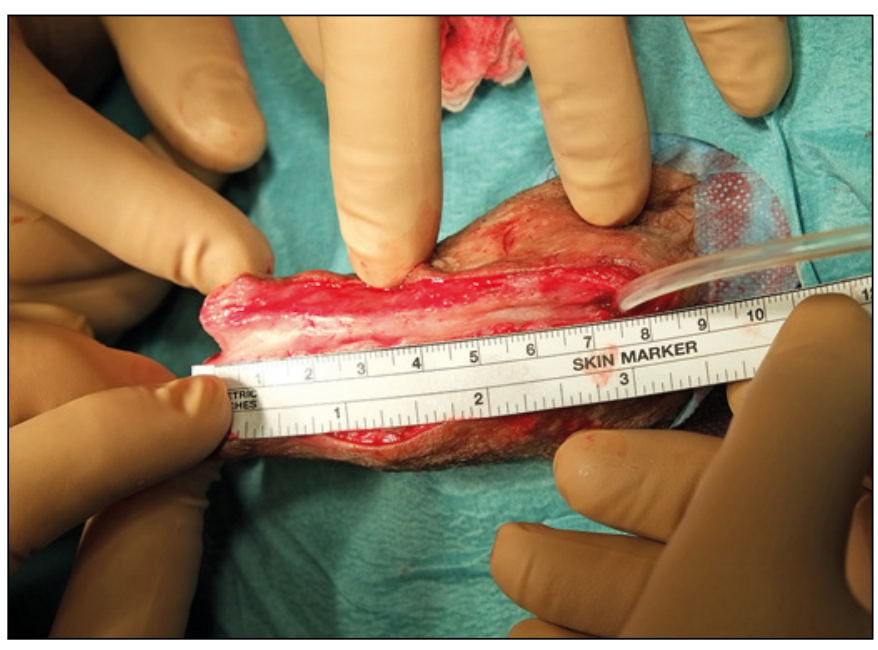

Figure 4. On ventral surface of penis skin, tunica dartos and urethra are incised in the midline. Urethral stricture length is $7 \mathrm{~cm}$.

cosa graft was harvested after a mouth retractor was placed, the oral mucosa disinfected and the orifice of Stenon `s duct identified and marked. The desired oval shape of the graft was marked on the inner surface of cheek. Lidocaine HCL $1 \%$ with epinephrine $(1: 100000)$ was injected under the mucosa and the graft was dissected. After hemostasis the mucosal wound was closed with 4/0 polyglactin absorbable running suture. The graft was defatted, tailored and placed in a small bowl with $0.9 \% \mathrm{NaCl}[19,20]$. The buccal mucosa graft was sutured to the margins of the separated wings of the urethral plate and anchored into the tunica albuginea by $5 / 0 \mathrm{ab}-$ sorbable sutures (Figure 6). The urethra was then tubularized in two layers with running $4 / 0$ polyglactin absorbable sutures over Foley catheter (14 Fr) which was left for 3 weeks. The operative wound was closed in multiple layers (Figure 7). A suprapubic drain (15 Fr) was left in the bladder and re- 


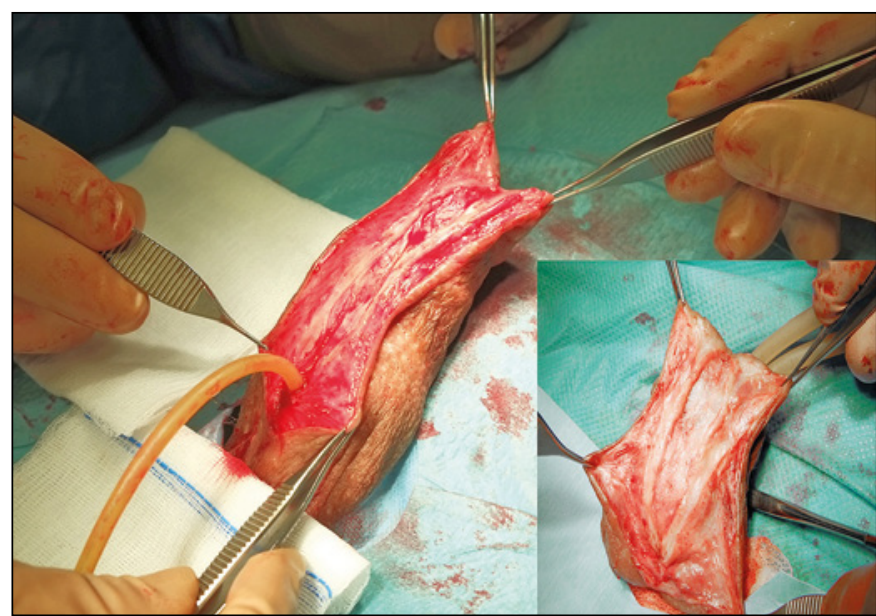

Figure 5. Dorsal urethral wall is incised in the midline to expose tunica albuginea of corpora cavernosa. Lateral mobilization of two parts of urethral plate is started (on the left side). In the right lower quadrant a bed for buccal mucosa graft implantation is prepared (during photo taking the penile base is compressed with a tourniquet).

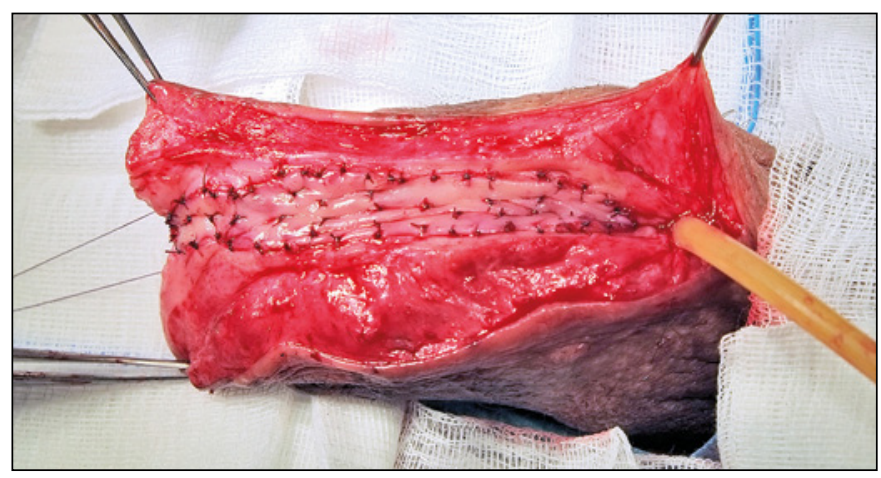

Figure 6. Buccal mucosa graft is sutured to separated margins of two parts of the urethral plate and anchored into tunica albuginea.

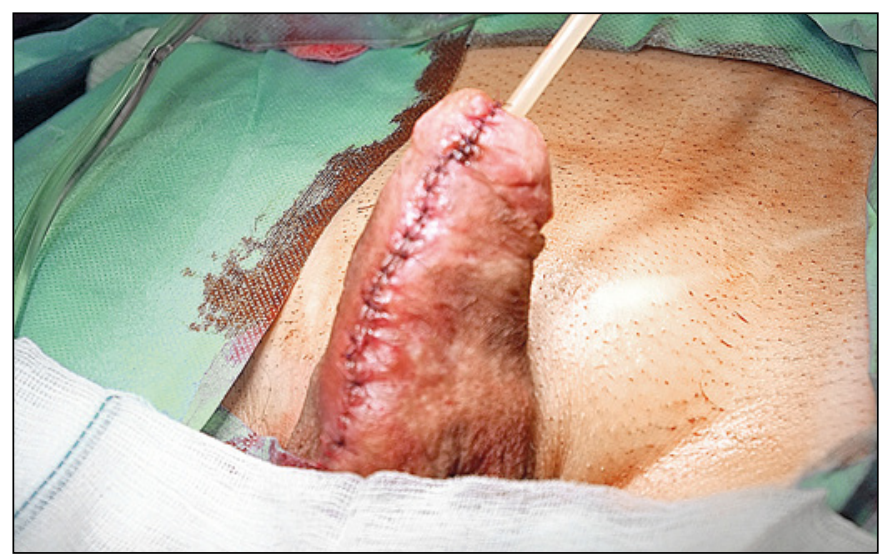

Figure 7. Penis after the operation, catheter size $14 \mathrm{Fr}(4.7 \mathrm{~mm})$ is introduced into the bladder. Urethra is closed in two layers, penis is sutured in multiple layers. moved a few days after the Foley catheter had been withdrawn and after the patient could void without problems.

According to the method by Barbagli [19, 20], a single-stage dorsal onlay BMGU was performed in 2 patients with US in bulbar urethra. The operation was performed under general anesthesia, in the lithotomy position, a midline perineal incision was made and bulbocavernous muscle was dissected from corpus spongiosum and retracted. The distal part of bulbar urethra was dissected from corpora cavernosa and the urethra was rotated by 180 degrees. The dorsal urethral surface was incised in the midline until the urethral lumen and the catheter were seen. The segment of the urethra with a stricture was incised distally and proximally and a buccal mucosal graft was sutured and anchored to the tunica albuginea of corpora cavernosa. A Foley catheter $(16 \mathrm{Fr})$ was introduced into the bladder and left for 3 weeks. The bulbar urethra was rotated over the graft and its margins were sutured around the graft to the tunica albuginea using 4/0 absorbable sutures. The bulbocavernous muscle was pulled back into its anatomical position. The operative wound was closed in multiple layers. A suprapubic drain (15 Fr) was always left in the bladder.

Mean length of US measured intraoperatively was $5 \mathrm{~cm}$ (range from 2.5 to $9.0 \mathrm{~cm}$ ).

The first calibration of the urethra was done one month after the operation with a sterile hegar covered with ASG (Contractubex gel, Merz Pharmaceuticals $\mathrm{GmbH}$, Germany, whose main components per $1 \mathrm{~g} / \mathrm{gel}$ are: onion extract $100 \mathrm{mg}$, sodium heparin $50 \mathrm{IU}$, and allantoin $10 \mathrm{mg}$ ). Before calibration, the distal part of the penis with external urethral meatus were always disinfected with Octenisept (Schülke\&Mayr GmbH, Germany) whose main components per $100 \mathrm{~g}$ are octenidinum dihydrochloridum $0.10 \mathrm{~g}+$ phenoxyethanolum $2.0 \mathrm{~g}$. Prior to the preventive calibration the authors measured inner urethral size (IUS) choosing a hegar which could be introduced with ease, gently and without any resistance. A calibration was done by a straight hegar (working length $-12 \mathrm{~cm}$ ) which was introduced starting from size $3.5 \mathrm{~mm}$ (diameter in millimeters) or, if possible, by hegar size $4.0 \mathrm{~mm}$ (if introduced with ease). The tip of the hegar was inserted approximately $2 \mathrm{~cm}$ behind the proximal end of the former US. The patient was instructed in detail how to disinfect the calibrator at home (patients should wipe the hegar with a sterile gauze soaked with Octenisept for one minute and then should spray the calibrator with Octenisept for another minute) and in case of distal penis with external urethral meatus (patients should wipe the skin and the urethral meatus 


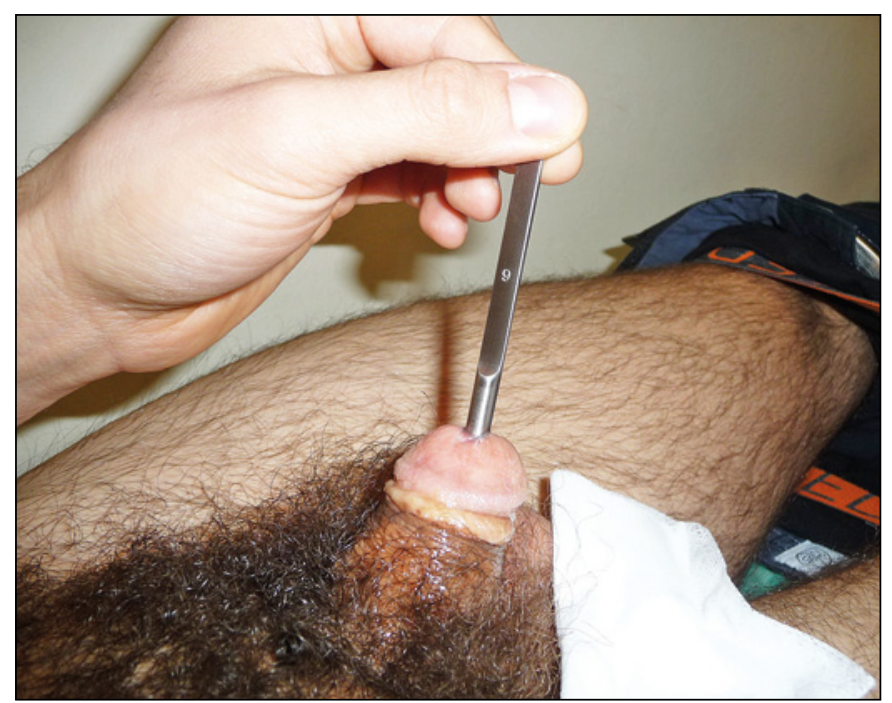

Figure 8. Calibrator size 6.0 introduced into urethra by the patient 9 months after BMGU.

BMGU - buccal mucosa graft urethroplasty

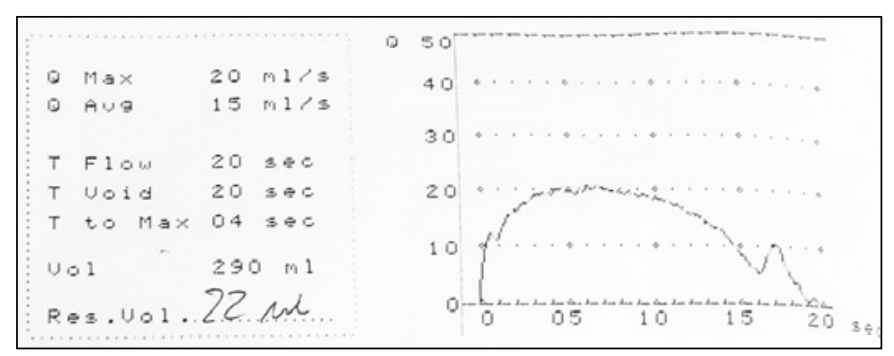

Figure 9. Uroflowmetry 1 year after the operation:

Qmax - $20.0 \mathrm{ml} / \mathrm{s}, Q a v g-15.0 \mathrm{ml} / \mathrm{s}$, flow time - $20.0 \mathrm{~s}$, voided volume - $290.0 \mathrm{ml}$, PVR - $22.0 \mathrm{ml}$.

Qmax-maximal urethral flow; Qavg - average urethral flow; PVR-post-void residual volume

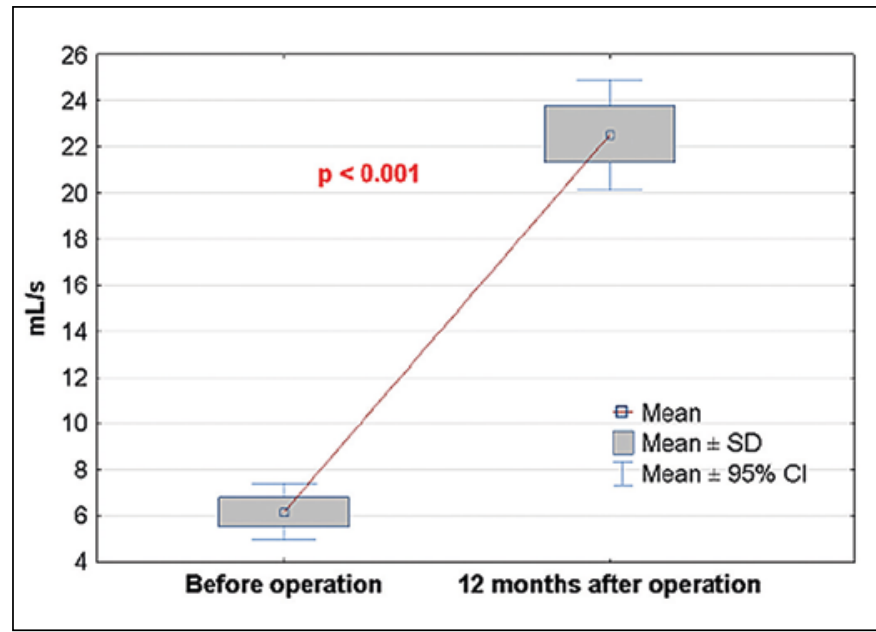

Figure 10. Mean Qmax before operation increased from $6.16 \mathrm{ml} / \mathrm{s}$ to $22.53 \mathrm{ml} / \mathrm{s}, p<0.001,12$ months after operation. Qmax-maximal urethral flow with a sterile gauze soaked in Octenisept for one minute and then should spray this area with Octenisept for another minute). Then the patients were instructed how to cover the hegar with ASG and how to introduce it practicing it several times until it is easy for them. If after calibration some ASG is left around the urethral orifice, patients are asked to cover the hegar with it and introduce the hegar into the urethra again. After calibration, the hegar was cleaned from ASG by gauze soaked with Octenisept, patients took the chosen calibrator with them in an unsterile plastic bag and performed disinfection described above before each calibration done at home. The hegar was inserted 1 to 2 times a day for 4-6 weeks. After that time, authors - during consultation - calibrated urethra by hegar of the next size (increased by $0.5 \mathrm{~mm}$ ) and the same procedure for 4-6 weeks was recommended. At this stage the patients were asked to introduce additionally 2-3 drops (0.4-0.6 ml) of ASG into urethral orifice with a syringe before each calibration. Then every 4-6 weeks size of calibrator is increased to $4.5 \mathrm{~mm}$, $5.0 \mathrm{~mm}, 5.5 \mathrm{~mm}$, or sometimes even to $6.0 \mathrm{~mm}$ (Figure 8 ). The largest possible hegar can be introduced 6-8 months after the operation.

Uroflowmetry and urethral calibration were used as an objective outcome measurement method. One month before uroflowmetry, calibrations of urethra were stopped. After that, the examined patients were instructed to calibrate urethra with ASG twice a week for 6 months, then once a week for 6 months, followed by a calibration once a month. A follow-up

Table 3. Results of BMGU and routine postoperative treatment with ASG, last follow-up consultations - June 2019

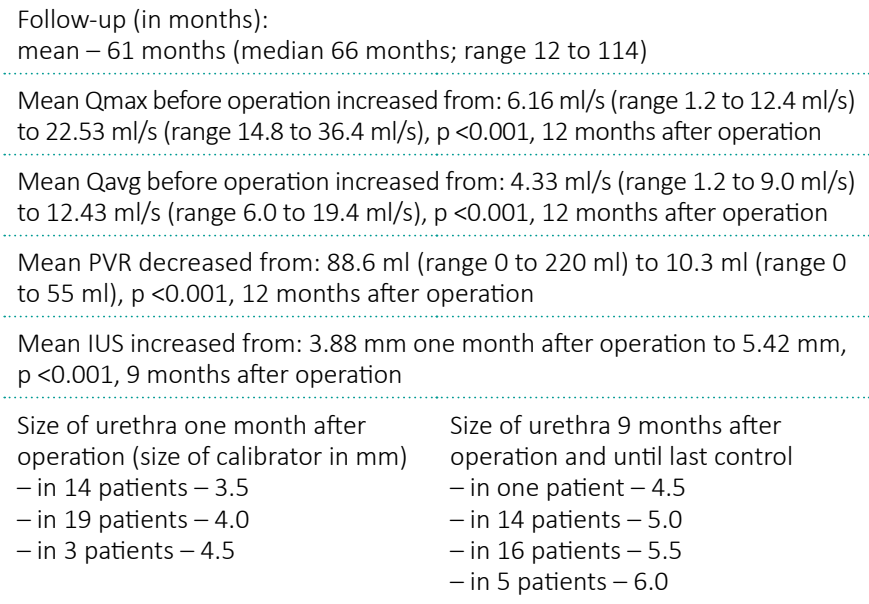

Mean PVR decreased from: $88.6 \mathrm{ml}$ (range 0 to $220 \mathrm{ml}$ ) to $10.3 \mathrm{ml}$ (range 0 to $55 \mathrm{ml}$ ), $\mathrm{p}<0.001,12$ months after operation

Mean IUS increased from: $3.88 \mathrm{~mm}$ one month after operation to $5.42 \mathrm{~mm}$, $\mathrm{p}<0.001,9$ months after operation

$$
\begin{array}{ll}
\text { Size of urethra one month after } & \text { Size of urethra } 9 \text { months after } \\
\text { operation (size of calibrator in } \mathrm{mm} \text { ) } & \text { operation and until last control } \\
\text { - in } 14 \text { patients }-3.5 & - \text { in one patient }-4.5 \\
\text { - in } 19 \text { patients }-4.0 & - \text { in } 14 \text { patients }-5.0 \\
\text { - in } 3 \text { patients }-4.5 & - \text { in } 16 \text { patients }-5.5 \\
& - \text { in } 5 \text { patients }-6.0
\end{array}
$$

urethral sticture during follow-up -0 , urethrocutaneous fistula - 0

BMGU - buccal mucosa graft urethroplasy; Qmax - maximal urethral flow; Qavg - average urethral flow; PVR - post-void residual volume; IUS - inner urethral size 
with a calibration of the urethra with the last adjusted hegar was done annually and additionally on patient request. Final information was gathered from patients (via telephone, email) by June 2019.

\section{Statistical methods}

Means and ranges of maximum urethral flow rate (Qmax) and of average urethral flow rate (Qavg) before and after operation were statistically assessed by parametric t-student test. Means and ranges of post-void residual volume (PVR) before and after operation and inner urethral size (IUS) one and 9 months after operation were statistically assessed by nonparametric 1-sample Wilcoxon signed rank test. A p-value of $<0.05$ was defined to be statistical-

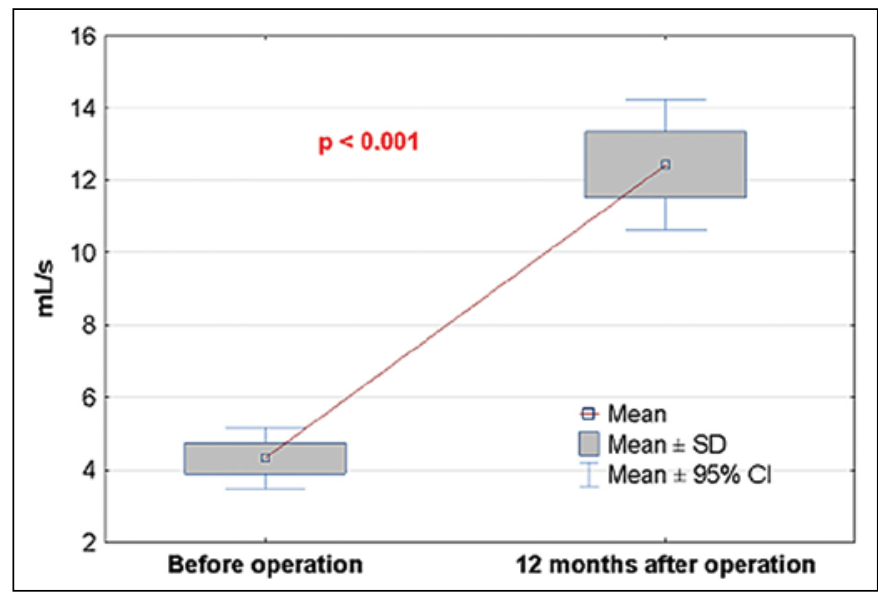

Figure 11. Mean Qavg before operation increased from $4.33 \mathrm{ml} / \mathrm{s}$ to $12.43 \mathrm{ml} / \mathrm{s}, p<0.001,12$ months after operation. Qavg-average urethral flow

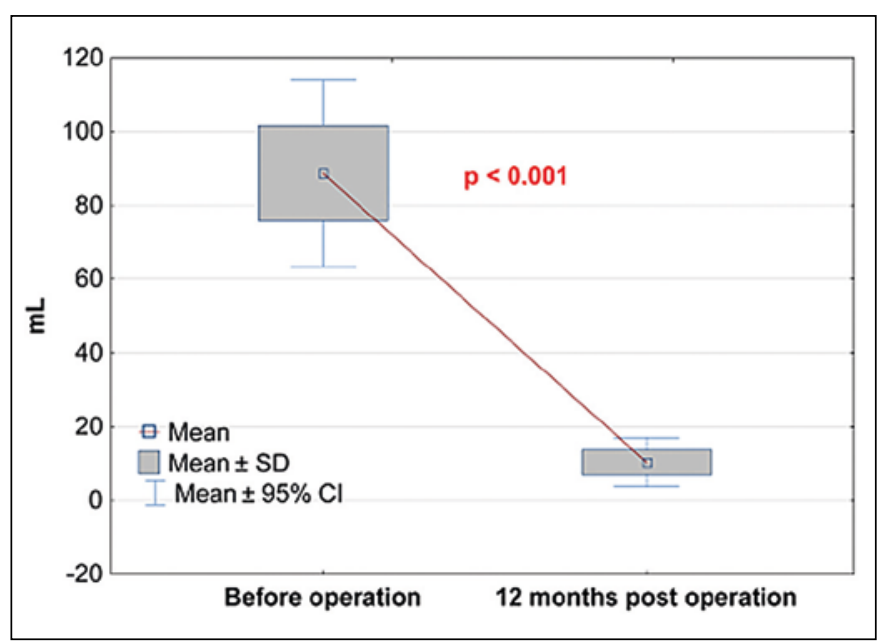

Figure 12. Mean PVR before operation decreased from $88.6 \mathrm{ml}$ to $10.3 \mathrm{ml}, p<0.001,12$ months after operation. $P V R$ - post-void residual volume ly significant. All analyses were done with Statistica 12.5 (StatSoft, Poland).

\section{RESULTS}

Mean follow-up was 61 months (median 66 months; range 12 to 114 months).

Uroflowmetry confirmed that BMGU and a calibration with ASG improved voiding in all patients (Figure 9). The results of the operations are presented in Table 3. Preoperative mean Qmax (Figure 10) and mean Qavg (Figure 11) increased significantly, $\mathrm{p}<0.001$, at 12 months after the operation. Preoperative mean PVR decreased significantly, $\mathrm{p}<0.001$, at 12 months after the operation (Figure 12). From the first month after the operation, mean IUS increased significantly, $\mathrm{p}<0.001$, at 9 months after the operation (Figure 13). No recurrent US or urethrocutaneous fistulas were detected in any patients. We did not observe any complications regarding the harvesting of buccal mucosa grafts. Signs of irritation connected with introducing the ASG into the urethra were not observed in any patient.

\section{DISCUSSION}

An important step in treatment of a long segment and recurrent anterior US is BMGU, also considered the 'gold standard' $[1,2,6,9]$. In spite of that, the stricture recurrence rate in the penile part of the anterior urethra, especially in patients operated on many times, is between $12 \%$ to $18 \%$ or even $31 \%$ $[1-6,9,11,16]$. Good results observed after BMGU decrease with time and US may recur after many years $[1,2,3,10,11,13]$. Stricture-free survival

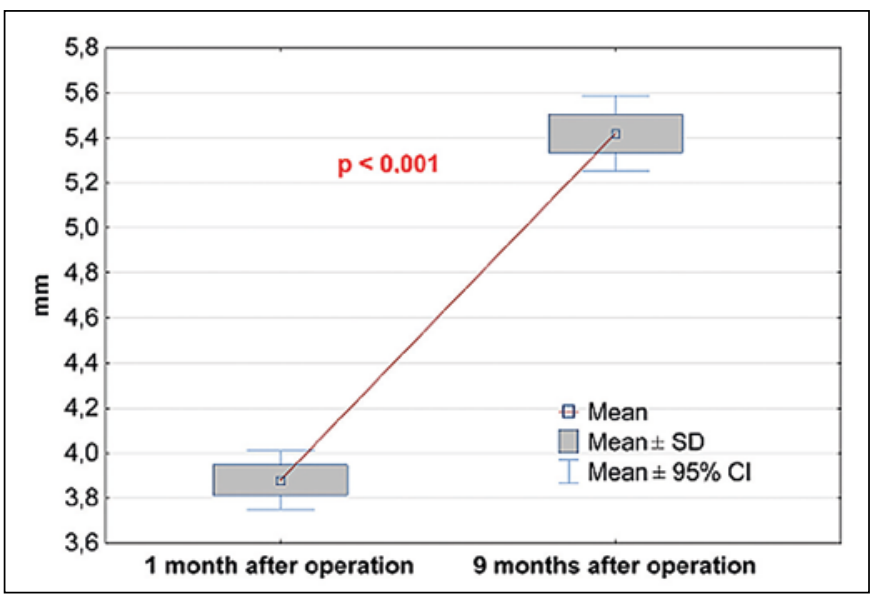

Figure 13. Mean IUS before operation increased from $3.88 \mathrm{~mm}$ one month after operation to $5.42 \mathrm{~mm}, p<0.001$, 9 months after operation.

IUS - inner urethral size 
at 12,24 and 36 months was $91.2 \%, 86.2 \%$ and $80.8 \%$, respectively [2]. During observation at 5,10 , 15 years after BMGU, restricture rates were $21 \%$, $31 \%$ and $58 \%$, respectively [16]. Most of the recurrences occurred in the first 2 years of follow-up $[3,11]$. In patients after hypospadias repair leading a normal sexual life, origin of US may partly be explained by mechanical trauma of a non-elastic urethra formed from skin, not covered by corpus spongiosum $[1,6,21]$.

The recurrence rate of US in $20 \%$ of patients 5 years after BMGU assessed as a good result by urologists, may be regarded quite differently from the patients point of view. The operation itself is the most important part of the treatment, but not the only factor which may influence the final result. The authors of this prospective study paid a lot of attention to postoperative treatment and included it into the comprehensive treatment of USD. This attitude was based on the thesis that the main reason of recurrent US were scars, which had been the result of wound healing, followed by scar contraction. For prevention of US, the authors proposed a routine calibration of the urethra with ASG, which began one month after BMGU. Understanding the physiology of wound healing and its consequences was very helpful in constructing our prospective study. Natural wound healing leads to scar formation, which joins tissues. As the urethra has a tubular shape, scars may narrow its diameter and make its wall rigid.

Wound healing is a process which includes:

- hemostasis (clot formation, lasts from a few minutes to a few hours),

- inflammation (lasts a few hours to a few days), infiltration by phagocytic neutrophils which invade the clot, remove debris, and prevent infection, which are then cleared by macrophages, thus enabling the anti-inflammatory, pro-repair state to begin $[22,23]$,

- proliferation (lasts 4-21 days),

- remodeling (lasts 21-365 days, or even several years) [23, 24].

The last two phases have a great influence on producing scars and need more detailed discussion. In the proliferation phase, migration of fibroblasts and endothelial cells results in the formation of granulation tissue. Fibroblasts gradually replace the provisional matrix with a collagen-rich matrix and transform into myofibroblasts [24, 25]. For proliferation, sufficient peripheral oxygen partial pressure is necessary. Extension of blood vessels allows oxygen to be transported into the wound to promote proliferation, form myofibroblasts, and generate tensile strength, which lead to contraction and further closure of the wound. In the next phase called re- modeling, a transition from the granulation phase to a relatively acellular, avascular collagen-rich scar is observed [22, 24, 25]. Type I collagen fibers are changed into thick bundles and the extracellular matrix is remodeled into a mature structure with greater integrity $[24,25]$. Due to myofibroblast contraction, wound strength increases gradually from $20 \%$ of normal tensile strength at 3 weeks after surgery, to about $70-80 \%$ within 2 years, mainly because collagen is a fragile substitute slowly restoring tissue continuity [23, 24, 26]. Dysregulation of these events can result in delayed wound healing and may form excessive scarring (1-2 months from injury), especially in areas of high tissue tension [23].

Lessons learned from wound healing can be useful after operations for recurrent US.

Inflammation appears to be substantially reduced in mucosal wounds as compared with dermal wounds, which explains why mucosal wounds heal more rapidly [27]. Prolonged or excessive local inflammatory response negatively influences the repair, slowing its progress or inducing excessive fibrosis and hypertrophic scarring $[22,28]$. Neutrophils are active in debris removal early in wound healing, but their persistence has been associated with delayed wound healing [23]. That is why all procedures which decrease the risk of postoperative infection should be undertaken. Patients with USD should not be operated on just after successful treatment of infection with antibiotics, but should be followed by a few weeks of prophylactic treatment, to give time for inflammation to subside. Postoperative treatment with antibiotics is mandatory. The use of a grooved Foley catheter, which facilitates the evacuation of blood or exudate from the urethra is preferred. Adequate arterial supply is critical for successful wound healing. Variations of oxygen tension (in tissues) can alter fibroblast proliferation and may lead to collagen overproduction and abnormal scars [29, 30]. If blood supply to the sutured tissues is decreased - like in the urethra (and tissues surrounding it) operated on many times - scars are hypertrophic. Wound healing which produces hypertrophic scars may lead to gradual urethral narrowing, making the wall noncompliant and rigid. A postoperative scar is fragile for at least 2 years after the operation, mainly because collagen slowly restores its tensile strength. Collagen can be easily broken not only before but also after that time [26]. The authors of this study never treat US by dilatations, which can cause rupture of collagen fibers present in the scar and provoke further deterioration. It is not rare that dilatations start from $8 \mathrm{Fr}$ increasing in size up to $24 \mathrm{Fr}$ (from circa $2.6 \mathrm{~mm}$ to $8.0 \mathrm{~mm}$, respectively) during a single procedure, sometimes followed by DVIU [31]. The 
improvement of Qmax can be observed comparing to preoperative levels but even in the first year Qmax is slowly decreasing. This is probably the reason why follow-up duration in papers describing dilatation or dilatation followed by DVIU is usually short [31]. The use of repeated instrumentations before BMGU is still depressingly common [16]. Some authors suggest that prior dilatations and DVIU result in nearly $100 \%$ stricture recurrence $[3,32]$ and they are reported as independent risk factors for failure after urethroplasty [11, 32].

Some surgeons exclude patients with USD after previous unsuccessful hypospadias repair and those with lichen sclerosus from series with other etiologies, expecting that results of operative treatment may be quite different among them [5, 12]. The authors of this study described the way of treatment of all consecutive patients coming to us with recurrent US without any exclusion. The management of the stricture of the penile urethra in patients in whom many operations for hypospadias failed is a challenge for reconstructive urologists $[1,9,17]$. Penile skin is scarred, immobile, hypovascular $[1,6$, 33 ], the urethra formed from skin is not elastic, covered by underdeveloped, divided corpus spongiosum, whose two atretic pillars could be rarely used to cover the neourethra [34]. Poor development of tunica dartos (used to cover neourethra) often accompanies severe forms of hypospadias [35]. That is why the urethra reconstructed from skin and covered by tissues, which does not preserve adequate vascular and mechanical support is prone to postoperative complications. The urethra may deteriorate after repeated stretches during erections and sexual activity, which may lead to US many years after the operation $[1,2$, 17]. At a median follow-up of 36 months, the overall success rate of Asopa single-stage dorsal inlay BMGU was $70 \%$ [5]. The restricture rates at 5, 10, and 15 years after BMGU were $21 \%, 31 \%, 58 \%$, respectively, indicating steady deterioration with time [16], observed also by others [14, 15], which stimulated us to look for treatment which would decrease that negative influence of time. We used preoperative, intraoperative and postoperative actions to meet that goal. In preoperative practice, massage of skin with the use of ASG was performed to decrease size of scars, increase their elasticity and to improve blood supply to superficial penile layers. Such treatment was continued for several weeks if the clinical situation allowed the operation to be postponed. It was important to introduce intraoperatively a grooved (if attainable) Foley catheter no greater than $14 \mathrm{Fr}$ with two goals: to decrease tissue tension on sutured urethra, having also in mind not to reduce the blood supply, especially to the inner (but not only) layer of the urethra, which would create two ways to reduce the formation of hypertrophied scars [23, 30, $36,37]$. A question arose if a Foley catheter (18 Fr) left in the urethra during Asopa operation would influence the results [5].

Operations for penile US can be performed in a single-stage or in two-stages; this depends on their location, length and the history of previous operations. This information is necessary for a surgeon who decides which method to choose $[1,2,4,6,9,17]$. There are surgeons who prefer to operate hypospadias in patients with USD in two or even more stages $[17,38]$. The information that one-stage BMGU or two-staged repair may give the same results, with success rate of $82 \%$ [1] was important for the authors of this study and helped us to decide that there was no reason to propose two-stage (changed often into multistage, if complications appear) repair in patients with a history of many failed operations. Patients were informed that after BMGU calibrations with ASG were planned (to decrease the possibility of US recurrence) if informed consent for calibration would be signed by them. The achieved good results (no single US, no fistula) confirmed our hypothesis that prolonged calibration with the use of ASG improved long-term results after BMGU in patients with recurrent USD.

Senior author (WP) has used ASG on postoperative scars (hypospadias, phimosis) for many years, even in small children with good effect, without observing adverse effects. There are reports which present safety of ASG treatment of scars on the skin [39] and even in experimental nerve anastomoses [40]. ASG itself prevents fibrosis (fibroblast inhibition) as well as postoperative scar contraction (extract of onion, which also has antibacterial activity), by loosening collagen structures and anti-inflammatory activity (heparin), by accelerating wound healing and epithelialization, increasing tissue permeability, which helps to penetrate deeper under skin or mucosa (allantoin) $[39,40]$. Because of the positive effects even on the delicate skin of children, one of the hypotheses of the present study was that ASG would also have a positive effect on healing of the urethral wall.

The authors used calibration with ASG for treatment of scars which were formed in the early stage of wound healing after BMGU, with the aim to prevent development of US in the long-term. The calibration is used for introducing ASG into the urethra as well as to distribute it regularly on the urethral mucosa avoiding concentration or conglomeration which may be the case if a simple injection of ASG through the tip of a syringe or a catheter into urethral orifice is used. Such conglomeration could be a source of problems with voiding. Patients were 
trained how to do this until they were able to perform calibration by themselves. Best results were achieved when patients do this calibration every day. Then, every 4-6 weeks hegar size was increased - if possible - by $0.5 \mathrm{~mm}$ with a recommendation for the next 4-6 weeks period of calibration. The preferred final hegar size was $5.0 \mathrm{~mm}$ or $5.5 \mathrm{~mm}$ but some patients continued calibration with size $6.0 \mathrm{~mm}$. If the final diameter of the urethra, under authors ' control was achieved, there was very low probability for US recurrence. Patients have a good tool for controlling their urethral diameter in the long-term, even for many years. They were asked to come for a control examination anytime they needed due to possible problems with voiding or due to problems in introducing a hegar into the urethra. The possibility of increasing the size of calibrators and elasticity of the urethra (increased Qmax, change of curve shape) convinced the authors that this practice is worth continuing.

Calibration itself acts passively by maintaining the diameter of the urethra and preventing diminishing its size during scar maturation. ASG itself acts actively, by loosening the scar and by preventing scar contraction. Between these two actions, a synergic effect can be observed.

During follow-up we used uroflowmetry and calibration of the urethra as objective criteria of results assessment. The first examination helped us to assess urethral elasticity and function (Qmax, Qavg, PVR). Mean Qmax and mean Qavg increased significantly, $\mathrm{p}<0.001$, mean PVR decreased significantly, $\mathrm{p}<0.001$, one year after the operation. Uroflowmetry was also used for follow-up by other authors [2, 6, 8, 13, 18]. Calibration was very useful in estimation of IUS, including its operated segment. From one month after the operation to 9 months after the operation IUS increased significantly, $p<0.001$. The authors of this study detected full patency of the urethra in operated patients in the long-term (from 12 to 114 months of observation). We did not observe diminishing of IUS comparing to that size assessed 9 months after the operation. As the length of the introduced hegar is $12 \mathrm{~cm}$ it was possible for the tip of the calibrator to reach the part of the urethra situated proximally to the graft and to the suture line (palpation is helpful). As urethral calibration may detect stricture recurrence early following urethroplasty [4] we could avoid invasive examinations for confirmation patency of the urethra $[1,6]$. In some series cystoscopy was done at least once (sometimes twice) during follow-up [3, 12]. In many publications the necessity of performing of any postoperative instrumentation is used as a definition of failure $[2,3,4,5,9,21]$. These authors have in mind the necessity of doing endoscopy with possible
DVIU, if voiding difficulties arise and Qmax is below $14-15 \mathrm{ml} / \mathrm{s}$. DVIU is a curative procedure which has the chance for success only if stricture is short (up to $1-1.5 \mathrm{~cm}$ ) and the incision is done once $[1,2,9]$. If incisions are longer or repeated many times they provoke fibrosis and US recurrence after such treatment is very high $[2,9,11]$. Postoperative prophylactic urethral calibration shouldn 't be included into that category. The risk of US in patients who have had failures after many urethral operations is big enough to justify prevention we proposed.

Prophylactic calibration as a part of a routine treatment should be differentiated from other instrumentations which are strictly therapeutic if US recurrence is confirmed.

In the authors' opinion BMGU as the 'gold standard' in long and recurrent anterior US could be enriched by calibration with ASG, understood as a routine postoperative procedure which may form comprehensive, broadened therapy of USD creating, together with BMGU, a new standard (gold standard plus?), especially for patients with restrictures. This supplementary method of treatment could also be used after primary operation of US. That opinion could be supported by reconstructive urologists who think that results after primary and redo operations are the same $(2,4,12)$. Postoperative calibrations with ASG could also be performed after the operations of USD in those older children or teenagers who can cooperate without fear with properly instructed parents.

\section{CONCLUSIONS}

Scars and their contraction during the postoperative period may be main causes of recurrent US after previous BMGU. Routine calibration with ASG has important influence on the early stage of wound healing, preventing scar contraction in the longterm. This treatment may be complementary to BMGU in US prevention. Calibration of the urethra with ASG is a safe and effective method of treatment for patients with USD who have had many urethral instrumentations and operations. Patients are very motivated to continue self-calibration because they suffered a lot for a long period of time due to serious problems with voiding as well as due to the painful memory of many operations.

\section{ACKNOWLEDGEMENTS}

Authors thanks Mr. Augustyn Szczawiński for great and invaluable help in revising our publication.

\section{CONFLICTS OF INTEREST}

The authors declare no conflicts of interest. 


\section{References}

1. Barbagli G, De Angelis M, Palmintieri E, Lazzieri M. Failed hypospadias repair presenting in adults. Eur Urol. 2006; 49: 887-895.

2. Rosenbaum CM, Schmid M, Ludwig TA, et al. Redo buccal mucosa graft urethroplasty: success rate, oral morbidity and functional outcomes. BJU Int. 2016; 118: 797-803.

3. Han JS, Liu J, Hofer MD, et al. Risk of urethral stricture recurrence increases over time after urethroplasty. Int J Urol. 2015; 22: 695-699.

4. Soave A, Kluth L, Dahlem R, et al. Outcome of buccal mucosa graft urethroplasty: a detailed analysis of success, morbidity and quality of life in a contemporary patient cohort at a referral center. BMC Urol. 2019; 19: 18.

5. Zumstein V, Dahlem R, Kluth LA, et al. A critical outcome analysis of Asopa single-stage dorsal inlay substitution urethroplasty for penile urethral stricture. World J Urol. 2019 Jul 18. doi: 10.1007/ s00345-019-02871-y [Epub ahead of print].

6. Barbagli G, Perovic S, Djinovic R, Sansalone S, Lazzeri M. Retrospective descriptive analysis of 1,176 patients with failed hypospadias repair. J Urol. 2010; 183: 207-211.

7. Morey AF, Duckett CP, McAninch JW. Failed anterior urethroplasty: guidelines for reconstruction. J Urol. 1997; 158: 1383-1387.

8. Joseph JV, Andrich DE, Leach CJ, Mundy AR. Urethroplasty for refractory anterior urethral stricture. J Urol 2002; 167: 127-129.

9. Jasionowska S, Brunckhorst O, Rees RW, Muneer A, Ahmed K: Redo-urethroplasty for the management of recurrent urethral strictures in males: a systematic review. World J Urol. 2019; 37: 1801-1815.

10. Hoy NY, Kinnaird A, Rourke KF. Expanded use of dorsal onlay augmented anastomotic urethroplasty with buccal mucosa for long segment bulbar urethral strictures: analysis of outcomes and complications. Urology. 2013; 81: 1357-1361.

11. Breyer BN, Mc Aninch JW, Whitson JM, et al. Multivariate analysis of risk factors for long-term urethroplasty. J Urol. 2014; 183: 613-617.
12. Levine M.A., Kinnaird AS, Rourke AS. Revision urethroplasty success is comparable to primary urethroplasty: a comparative analysis. Urology. 2014; 84: 928-933.

13. Andrich DE, Mundy AR. Substitution urethroplasty with buccal mucosal-free grafts. J Urol. 2001; 165: 1131-1133

14. Barbagli G, Kulkarni SB, Fossati, et al. Long-term follow-up and deteriorationrate of anterior substitution urethroplasty. J Urol. 2014; 192: 808-813.

15. Wood DN, Andrich DE, Greenwell TJ, Mundy AR. Standing the test of time: longterm results of urethroplasty. World J Urol. 2006; 24: 250-254.

16. Andrich DA, Dunglison N, Greenwell TJ, Mundy AR. The long-term results of urethroplasty. J Urol. 2003; 170: 90-92.

17. Meeks JJ, Ericson BA, Gonzalez CM. Staged reconstruction of long segment urethral strictures in men with previous pediatric hypospadias repair. J Urol. 2009; 181: 685-689.

18. Asopa HS, Garg M, Singhal GG, Singh L, Asopa J, Nischal A. Dorsal free graft urethroplasty for urethral stricture by ventral saggital urethrostomy approach. Urology. 2001; 58: 657-659.

19. Barbagli G, Selli C, Tosto A, Palminteri E. Dorsal free graft urethroplasty. J Urol. 1996; 155: 123-126.

20. Barbagli G, Morgia G, Lazzeri M. Dorsal onlay graft urethroplasty using penile skin or buccal mucosa in adult bulbourethral strictures. J Urol. 1998; 160: 1307-1309.

21. Meeks JJ, Ericson BA, Granieri MA, Gonzalez CM. Stricture recurrence after urethroplasty: a systematic review. J Urol. 2009; 182: 1266-1270.

22. Martin P, Leibovich SJ. Inflammatory cells during wound repair: the good, the bad, the ugly. Trends Cell Biol. 2005; 15: 599-607.

23. Ellis S, Lin E J,Tartar D. Immunology of Wound Healing. Curr Dermatol Rep. 2018: 7: 350-358.

24. Kawasumi A, Sagawa N, Hayashi S, Yokoyama H, Tamura K. Wound healing in mammals and amphibians: toward limb regenerations in mammals. Curr Top Microbiol Immunol. 2013; 367: 33-49.
25. Enoch S, Price PE. Cellular, molecular and biochemical differences in the pathophysiology in healing between acute wounds, chronic wounds and wounds in the aged. World Wide Wounds. 2004; pp. 1-16.

26. Rangaray A, Harding KG. Role of collagen in wound management. Wounds. 2011; 7: 54-63.

27. England ChD, Bosh JA, Cacioppo JT, Marucha PT. Mucosal wound healing. The roles of age and sex. Arch Surg. 2006; 141: 1193-1197.

28. Wang J, Jiao H, Stewart TL, Shankowsky HA Scott PG, Tredget EE. Increased TGFbeta producing CD4+ T Lymphocytes in postburn patients and their potential interaction with dermal fibroblasts in hypertrophic scarring. Wound Rep Regen. 2007; 15: 530-539.

29. Hunt T, Pai M. The effect of varying ambient oxygen tensions on wound metabolism and collagen synthesis. Surg Gynecol Obstet. 1975; 135: 561-567.

30. Gault S. Scars and contractures. Surgery. 1999; 17: 73-75.

31. Nomicos M, Papanicolau S, Asthanasopoulos $\mathrm{G}$, Papatsoris A. The use of Amplatz renal dilators in minimally invasive management of complex urethral strictures. Cent Eur J Urol. 2017; 70: 301-307.

32. Heyns CF, Steencamp JW, De Kock ML, Whitaker P. Treatment of male urethral strictures: is repeated dilation or internal urethrotomy useful? J Urol. 1998; 160: 356-358.

33. Stecker JF, Horton CE, Devine CJ, MCCraw JB: Hypospadias cripples. Urol Clin North Am. 1981; 8: 539-544.

34. Mouriquand PDE, Demede D, Gorduza D, Mure PY. Hypospadias. In Gearhart J, Rink R, Mouriquand PDE, editors. Pediatric Urology. 2nd ed. Philadelphia: WB Saunders 2010, pp. 526-543.

35. Spinoit AF, Buelens S, Van Praet Ch, Van Laecke E, Praet M, Hoebeke $P$. Influence of dartos tissue and androgen receptor in congenital penile malformations: opening new horizons in research with clinical relevance. Eur Urol Suppl. 2017; 16: 177-181.

36. Hunt TK, Pai MP. The effect of varying ambient oxygen tensions on wound 
metabolism and collagen synthesis. Surg Gynec Obst. 1972; 135: 561-567.

37. Gordillo GM, Sen CK. Revisiting the essential role of oxygen in wound healing. Am J Surg. 2003; 186: 259-263.

38. Pfalzgraf $D$, Kluth $L$, Reiss P, Fisch $M$, Dahlem R. Staged urethroplasty: comparison of early functional results and quality of life in mesh graft and buccal mucosa technique. Can J Urol. 2013; 22: 7720-7726.

39. Willital GH, Heine $H$. Efficacy of Contractubex gel in the treatment of fresh scars after thoracic surgery in children and adolescents.
Int J Clin Pharmacol Res. 1994; 14: 193-202.

40. Kahoraman A,Kahveci R. Evaluating the effect of polytetrafluoroethylene and extractum cepae-heparinallantoine gel in peripheral nerve injuries in a rat model. Plast Surg. 2015; 23: 9-14. 